\title{
DISTRIBUSI MOLEKULER SPESIES HETEROATOM DALAM MINYAK BATUBARA INDONESIA
}

\author{
Sri Djangkung Sumbogo Murti ${ }^{1)}$ dan Yusnitati ${ }^{2)}$ \\ 1) Balai Besar Teknologi Energi, B2TE, Puspiptek, Serpong \\ 2) Pusat Teknologi Pengembangan Sumberdaya Energi, BPPT \\ E-mail: sumbogomurti@yahoo.com
}

\begin{abstract}
Heteroatom-containing species in the coal liquid oils (CLO) were identified and quantified by the aid of gas chromatography with atomic emission detector (GC$A E D$ ). Four different CLOs from different rank coals, processes and cut points were investigated in the present study. Thiophene and its derivatives were found to be the major sulfur compounds, pyridines and anilines, and phenols were the major nitrogen and oxygen compounds, respectively in the oils of boiling range $\left.<300^{\circ} \mathrm{C}\right)$. An oil of boiling range $\left(300-420^{\circ} \mathrm{C}\right)$ carried more dimethyldibenzothiophenes and benzoquinolines. The correlation between feed coal and liquid product was discussed in terms of the compositions of heteroatomic compounds.
\end{abstract}

Kata kunci: coal liquid oil, heteroatomic compounds, GC-AED

\section{PENDAHULUAN}

Kebutuhan bahan bakar cair untuk transportasi yang semakin meningkat saat ini terutama masih bergantung pada produk minyak bumi. Pasokan minyak mentah tidak akan sebanding dengan permintaan terhadap energi yang semakin meningkat di masa yang akan datang. Oleh karena itu dibutuhkan alternatif bahan bakar cair selain dari produk minyak bumi. Pencairan batubara bisa menjadi salah satu alternatif untuk menghasilkan bahan bakar cair sehingga bisa mengurangi ketergantungan terhadap produk minyak bumi yang semakin terbatas (I.Mochida et.al., 1998).

Minyak batubara yang setara fraksi minyak disel cenderung memiliki heteroatom yang lebih banyak seperti sulfur, nitrogen dan oksigen (S.Yanai et.al., 1998). Kandungan heteroatom yang lebih tinggi menyebabkan masalah serius dalam menghasilkan polutan dan menyebabkan stabilitas yang rendah saat penyimpanan. Lebih jauh lagi, mereka dapat berperan sebagi inhibitor dan racun dalam proses pengilangan katalitik yang biasanya menggunakan katalis molybdenum atau tungsten sulfida dengan promotor cobalt atau nikel pada support alumina atau silika alumina (T.G.Albro et.al., 1993; M.Dorbon et.al., 1984; A.Z.Fathoni et.al., 1992; D.D. Whitehurst et.al., 1998 \& J.M.Schmichitter, 1980).

Perhitungan kandungan spesies heteroatom molekuler dalam minyak batubara sangat dibutuhkan untuk menjelaskan peranan dan perilaku kimianya pada proses hydrotreatment. Analisa kandungan molekuler dari spesies sulfur dalam minyak ringan dan reaktivitasnya telah dilaporkan. Meskipun GC-MS dapat digunakan untuk mengukur semua spesies, identifikasi semua spesies molekuler sangat membosankan.

Kajian ini melaporkan distribusi senyawa yang mengandung heteroatom (sulfur, nitrogen dan oksigen) dalam minyak batubara dengan bantuan kromatografi gas yang dilengkapi dengan detektor emisi atom (GC-AED). AED adalah detektor multi unsur yang dapat mengukur lebih dari 20 unsur (T.G.Albro et.al., 1993 \& V.Quimby et.al., 1993). Sekarang AED telah digunakan untuk analisis kuantitatif senyawa sulfur, nitrogen dalam minyak ringan dan senyawa yang mengandung logam dalam minyak ringan vakum. Distribusi molekuler spesies heteroatom bisa menunjukkan karakteristik komposisional dari batubara awal, efisiensi proses pencairan untuk menghilangkan heteroatom dan cutting point-nya.

\section{EKSPERIMEN}

\subsection{Sampel Batubara Cair}

Minyak mentah yang digunakan dalam kajian ini berasal dari pilot plant pencairan batubara di Jepang menggunakan 4 batubara seperti yang terdaftar pada Tabel 1. Analisa dari keempat batubara mentah disajikan pada Tabel 2. Fraksi 
dasar dan non-dasar SBCL-B dipisahkan dengan ekstraksi asam.

Tabel 1. Analisis Ultimat Minyak Batubara

\begin{tabular}{|l|l|l|l|l|l|l|l|l|}
\hline $\begin{array}{l}\text { Minyak } \\
\text { batubara }\end{array}$ & Proses & t.d. $\left({ }^{\circ} \mathrm{C}\right)$ & $\mathrm{C}^{\mathrm{a}}$ & $\mathrm{H}^{\mathrm{a}}$ & $\mathrm{N}^{\mathrm{a}}$ & $\mathrm{S}^{\mathrm{a}}$ & $\mathrm{O}$ (diff) & $\mathrm{H} / \mathrm{C}$ \\
\hline $\begin{array}{l}\text { Banko } \\
\text { Selatan } \\
\text { (SBCL-A) }\end{array}$ & $\mathrm{NBCL}$ & $<300$ & 84.97 & 10.37 & 0.84 & 0.09 & 3.74 & 1.46 \\
\hline $\begin{array}{l}\text { Banko } \\
\begin{array}{l}\text { Selatan } \\
\text { (SBCL-B) }\end{array}\end{array}$ & $\mathrm{NBCL}$ & $300-420$ & 87.89 & 9.29 & 0.77 & 0.07 & 1.98 & 1.27 \\
$\begin{array}{l}\text { Adaro } \\
\text { (ADCL) }\end{array}$ & $\mathrm{NEDOL}$ & $<260$ & 87.78 & 10.16 & 0.35 & 0.10 & 1.61 & 1.39 \\
\hline $\begin{array}{l}\text { Tanitoharum } \\
(\mathrm{THCL})\end{array}$ & $\mathrm{NEDOL}$ & $<260$ & 86.84 & 10.84 & 0.84 & 0.05 & 2.23 & 1.50 \\
\hline $\begin{array}{l}\text { Ikejima } \\
(\mathrm{IJCL})\end{array}$ & $\mathrm{NEDOL}$ & $<260$ & 88.48 & 9.94 & 0.51 & 0.10 & 0.97 & 1.35 \\
\hline
\end{tabular}

a : \% berat ; diff : differences

Tabel 2. Analisis Batubara Mentah

\begin{tabular}{|l|l|l|l|l|l|l|}
\hline Batubara & $\mathrm{C}^{\mathrm{a}}$ & $\mathrm{H}^{\mathrm{a}}$ & $\mathrm{N}^{\mathrm{a}}$ & $\mathrm{S}^{\mathrm{a}}$ & $\begin{array}{l}\mathrm{O} \\
\text { (diff) }\end{array}$ & $\mathrm{H} / \mathrm{C}$ \\
\hline $\begin{array}{l}\text { Banko } \\
\text { Selatan }\end{array}$ & 71.3 & 5.4 & 1.3 & 0.5 & 21.5 & 0.91 \\
\hline Adaro & 74.2 & 5.2 & 0.9 & 0.0 & 19.7 & 0.84 \\
\hline Tanitoharum & 75.9 & 5.8 & 1.8 & 0.2 & 16.3 & 0.92 \\
\hline Ikejima & 81.8 & 6.1 & 1.4 & 1.4 & 9.3 & 0.89 \\
\hline
\end{tabular}

a : \% berat ; diff : differences

\subsection{Kromatografi Gas dengan Detektor Emisi Atom}

Identifikasi senyawa yang mengandung heteroatom dalam minyak batubara dilakukan menggunakan sistem kromatografi gas HP 6890 dengan split/splitless injector port dan detektor emisi atom HP G2350A. Pemisahan kromatografi dilakukan pada kolom kapiler HP-1MS sepanjang $30 \mathrm{~m}$ berdiameter dalam 0.32 dengan ketebalan lapis tipis $1.0 \mu \mathrm{m}(\mathrm{HP})$.

Emisi atomik karbon, sulfur, nitrogen dan oksigen pada 179, 181, 174 dan $171 \mathrm{~nm}$ digunakan untuk mendapat selektivitas yang tinggi. Dua kali injeksi $1 \mu \mathrm{L}$ dilakukan untuk setiap sampel. Injeksi pertama untuk penentuan karbon, sulfur dan nitrogen, sedangkan injeksi ke dua untuk oksigen. Hidrogen digunakan sebagai reagen gas utama untuk kedua analisis. Oksigen dan metan murni ditambahkan untuk analisa pertama sedangkan metana $10 \%$ dalam nitrogen untuk analisa selanjutnya. HP AED Chemstation digunakan untuk mengontrol GC-AED dan untuk melakukan perolehan data dan integrasi puncak.

\section{HASIL DAN PEMBAHASAN}

Gambar 1 menunjukkan kromatogram karbon, sulfur, nitrogen dan oksigen dari SBCL yang diukur dengan GC-AED. Tiofen dan turunan dibenzotiofen adalah senyawa utama yang teridentifikasi dalam SBCL. Piridin, aniline dan fenol dan turunannya masing-masing senyawa nitrogen dan oksigen.

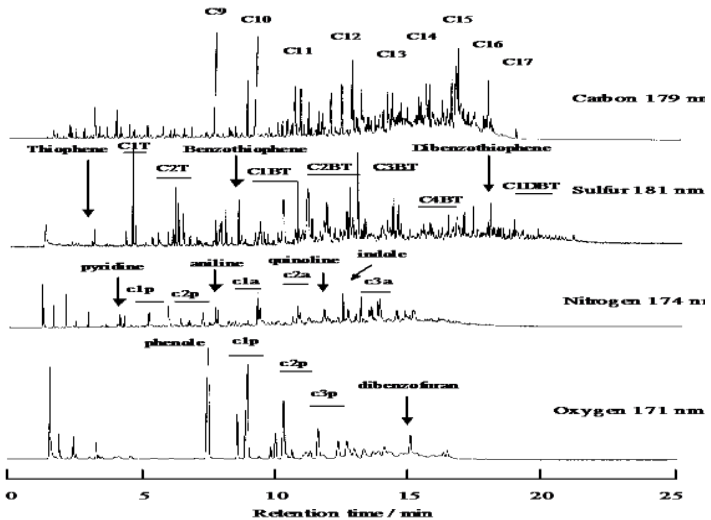

Gambar 1. Tampilan chromatogram dari carbon, sulfur, nitrogen and oksigen species in SBCL

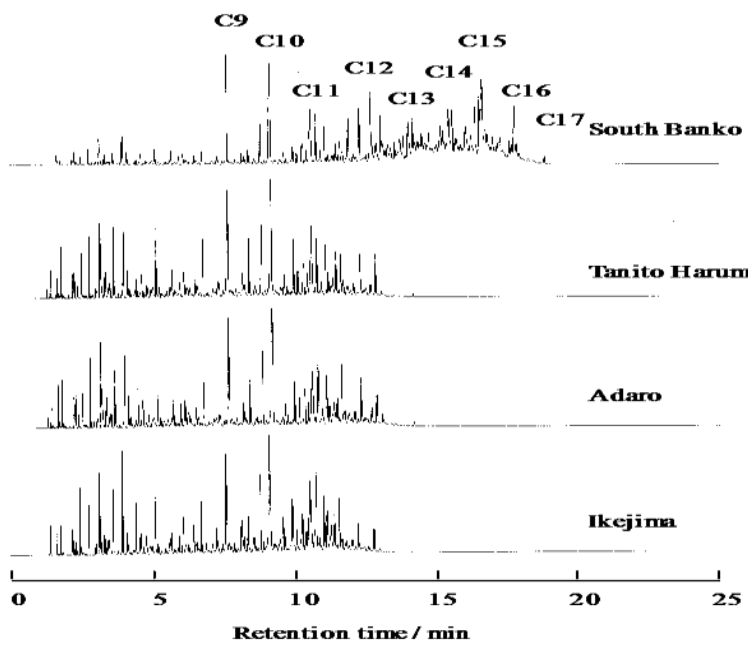

Gambar 2. Tampilan chromatogram GC-AED carbon dalam minyak batubara cair (coal liquid oil)

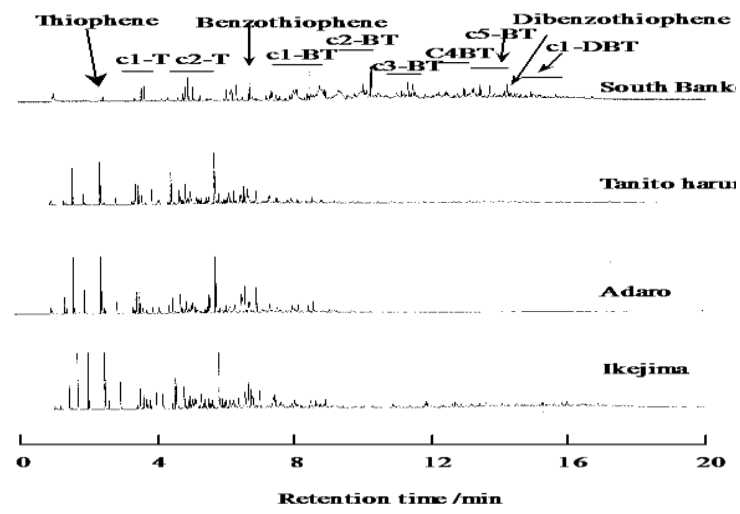

Gambar 3. Tampilan chromatogram GC-AED sulfur in minyak batubara cair (coal liquid oil 

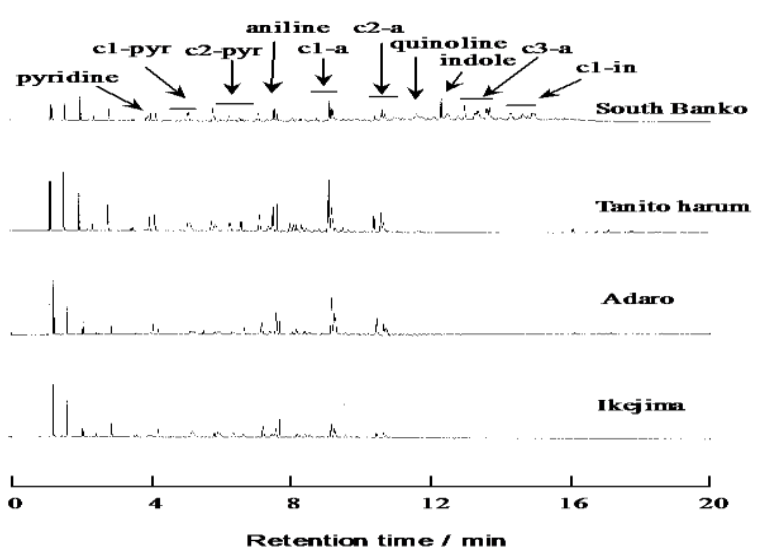

Gambar 4. Tampilan chromatogram GC-AED nitrogen dalam minyak batubara cair (coal liquid oil)

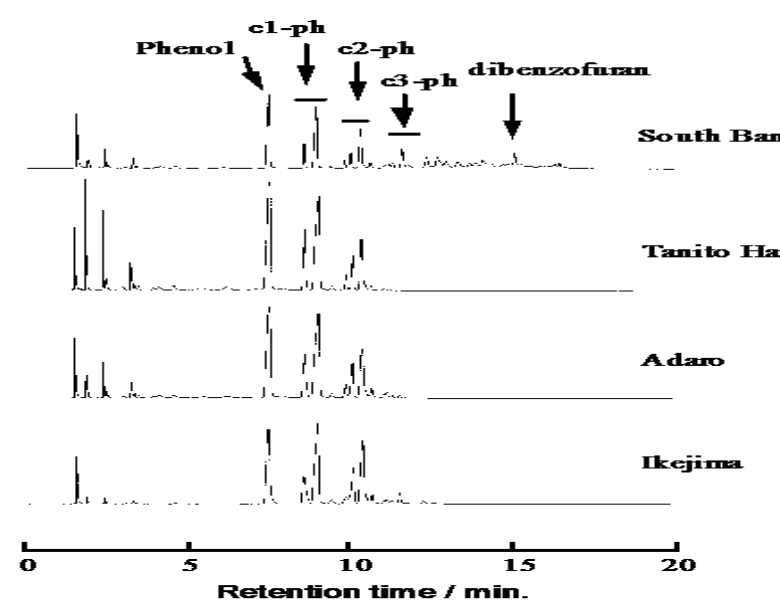

Gambar 5. Tampilan chromatogram GC-AED oksigen dalam minyak batubara cair (coal liquid oil)

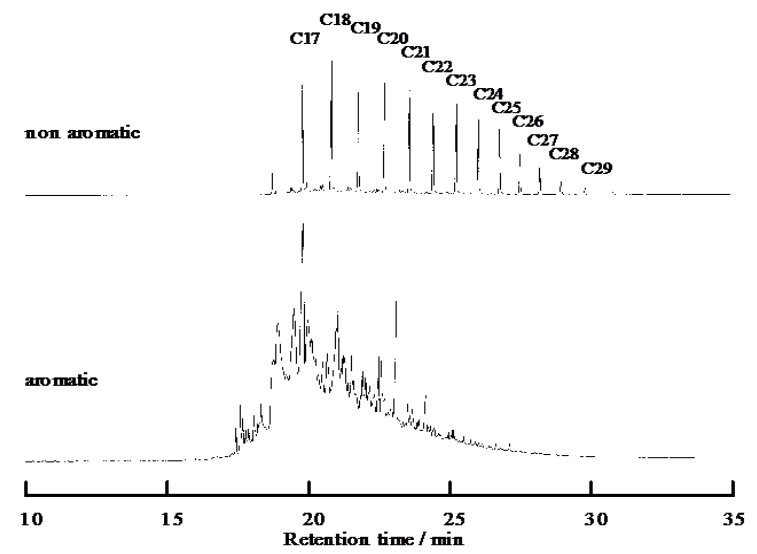

Gambar 6. Tampilan chromatogram AED senyawa hidrokarbon aromatik dan non aromatik dalam SBHD

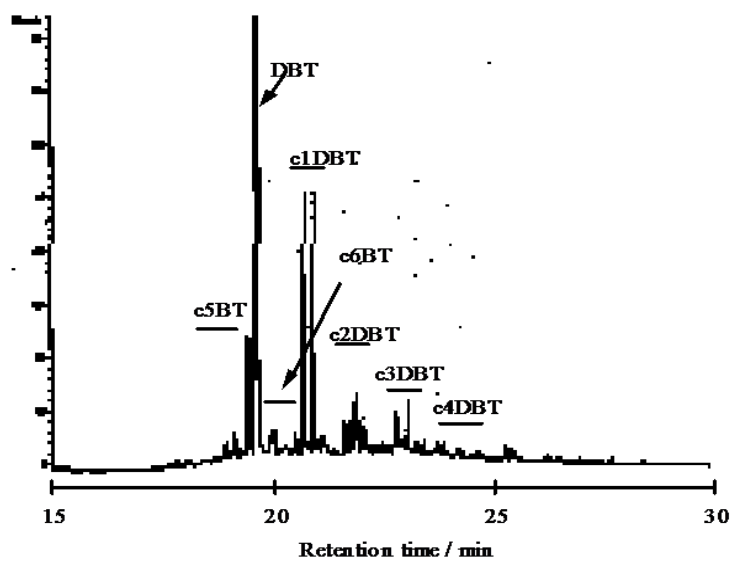

Gambar 7. Tampilan chromatogram AED senyawa sulfur dalam SBHD

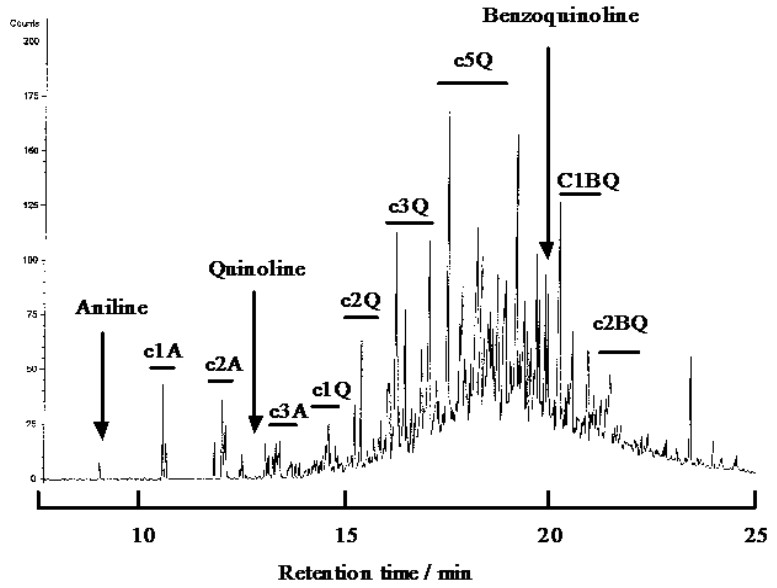

Gambar 8. Tampilan chromatogram AED senyawa nitrogen dasar dalam SBHD

Kromatogram karbon dari keempat minyak batubara ditunjukkan pada Gambar 2. Sampel mengandung hidrokarbon parafinik sampai $\mathrm{C} 17$ untuk SBCL-A karena titik didih akhirnya $300^{\circ} \mathrm{C}$ dan $\mathrm{C} 12$ untuk sampel yang lain dengan cutting point $260^{\circ} \mathrm{C}$. Hidrokarbon C9 dan $\mathrm{C} 10$ ditemukan sebagai puncak tertinggi dalam sampel terakhir. Kromatogram senyawa sulfur dalam distilat minyak batubara ditunjukkan pada Gambar 3. Spesies sulfur yang teramati dalam minyak batubara sebagian besar adalah tiofen dan tiofen tersubstitusi alkil. Kandungan tiofen dalam SBCLA relatif kecil dibanding tiga minyak batubara lainnya. Benzotiofen dan turunannya muncul dalam SBCL-A pada waktu retensi yang lebih lama karena titik didihnya yang lebih tinggi. Gambar 4 menunjukkan kromatogram nitrogen. Komponen nitrogen teridentifikasi dalam minyak batubara sebagian besar adalah piridin, aniline dan turunannya. quinolin, indol dan indol tersubstitusi alkil hanya ditemukan dalam SBCL. 
Kromatogram spesies oksigen dalam distilat minyak batubara ditunjukkan pada Gambar 5 . Fenol dan fenol tersubstitusi alkil adalah senyawa oksigen utama yang ditemukan dalam minyak batubara, meskipun dibenzofuran hanya teridentifikasi dalam SBCL-A.

Kromatogram SBCL-B ditunjukkan pada Gambar 6, Gambar 7 dan Gambar 8 masingmasing untuk karbon (hidrokarbon), sulfur dan nitrogen. Senyawa SBHD mengandung hidrokarbon parafinik dari C17 sampai C29. Senyawa dibenzotiofen (DBT) dan turunannya ditemukan sebagai spesies sulfur utama. Spesies dasar nitrogen teridentifikasi dalam SBHD sebagian besar adalah aniline, quinolin, benzoquinolin dan turunannya.

GC-AED mampu mengidentifikasi semua spesies molekuler dalam minyak batubara dengan jangkauan titik didih sampai $420^{\circ} \mathrm{C}$. Kandungan dan distribusi spesies yang mengandung heteroatom dalam minyak batubara menunjukkan proses pencairan, peringkat batubara umpan demikian juga titik didih meskipun biasanya yang terkandung adalah spesies yang sangat mirip. Kadar sulfur dari minyak Banko Selatan, Adaro dan Ikejima sama sekitar $0.1 \%$ berat, kecuali untuk Tanitoharum, meskipun kandungan sulfur dalam batubara dari tambang berbeda secara signifikan. Distribusi spesies sulfur dalam ketiga minyak berbeda. Minyak South Banko memiliki dimetil, trimetil BT dan dibenzotiofen pada titik didih $<300{ }^{\circ} \mathrm{C}$, sedangkan minyak Adaro dan Ikejima tidak memilikinya. Minyak Tanito Harum memiliki spesies yang mirip dengan Adaro dan Ikejima meskipun kadar sulfur minyak Adaro dan Ikejima lebih sedikit daripada minyak Tanito Harum. Perbedaan utama teramati pada kandungan tiofen.

Kandungan nitrogen nampak lebih berbeda dalam minyak. Minyak batubara memiliki nitrogen $0.4-0.9 \%$ berat, lebih besar daripada sulfur. Minyak batubara pada wilayah titik didih yang sama memiliki kandungan nitrogen masingmasing, yang menunjukkan kandungan dalam batubara mentah. Distribusi spesies nitrogen pada keempat minyak mirip meskipun SB memiliki quinolin dan indol karena titik didih yang lebih tinggi. Minyak TH memiliki lebih banyak anilin, metil dan dimetilanilin dibanding yang lain.

Kandungan oksigen dalam minyak batubara mencerminkan kandungan oksigen dari umpan awal. Minyak batubara memiliki kandungan oksigen $1-3.7 \%$ berat, yang merupakan heteroatom terbesar yang ditemukan. SB dengan kandungan oksigen paling tinggi menghasilkan lebih banyak senyawa oksigen dalam minyak. Ketiga umpan lain memiliki kandungan yang mirip. Selama proses pencairan, sebagian besar oksigen ditemukan sebagai fenol. Dibenzofuran diyakini sebagai spesies oksigen yang paling sulit dihilangkan yang ditemukan dalam minyak batubara SB.

Fraksi aromatik dan non-aromatik SBHD yang ditunjukkan dalam Gambar 6, dipisahkan menurut prosedur standar ASTM D-2549. Persentase fraksi aromatik dan non-aromatik masing-masing sebesar 82.1 dan $17.9 \%$. Jelas bahwa puncak yang ada menunjukkan fraksi aromatik. Terdapat puncak yang tumpang tindih dari aromatik, naftenik-aromatik padat, olefin aromatik dan spesies heteroatom seperti sulfur, nitrogen dan oksigen. Fraksi non-aromatik mengandung sederetan parafin normal.

SBCL-B yang memiliki titik didih lebih tinggi mengandung heteroatom yang lebih kompleks dan sebagian besar merupakan spesies yang sulit dihilangkan. Beberapa yang teridentifikasi adalah 4-metildibenzotiofen (61 ppm) dan 4,6dimetil dibenzotiofen (12 ppm). Benzoquinolin dan turunannya juga teridentifikasi sebagai spesies nitrogen utama. Beberapa senyawa heteroatom kompleks dengan tiga cincin benzene atau lebih diyakini sulit untuk dihilangkan dengan upgrading katalitik, menggunakan katalis komersial konvensional. Inhibitor seperti senyawa oksigen dan spesies dasar nitrogen dalam minyak batubara memaksa kita merancang katalis dan proses yang lebih baik untuk upgrading minyak mentah untuk bahan bakar transportasi.

\section{KESIMPULAN}

Kromatografi gas dengan detektor emisi atom sangat kuat untuk karakterisasi dan identifikasi spesies heteroatom dari seluruh spesies molekuler dalam minyak bumi dan minyak batubara. Tiofen, benzotiofen sebagai senyawa sulfur; piridin, aniline sebagai senyawa nitrogen; fenol sebagai senyawa oksigen teridentifikasi dalam minyak batubara dari titik didih yang lebih rendah. Dibenzotiofen, quinolin, indole, dibenzoquinolin, dibenzofuran dan turunannya hanya ditemukan dalam minyak batubara Banko Selatan karena titik didihnya lebih tinggi.

\section{DAFTAR PUSTAKA}

Albro, T. G., Dreifuss, P. A. , Wormsbecher, R. F., 1993. HRC \& CC. $16,13-17$

Dorbon, M., Ignatiadis, I., Schmitter, J. M., Arpino, P., Guichon, G., Toulhoat, H. A., 1984. Fuel 63, $565-570$.

Fathoni, A. Z., Batts, B. D. 1992. Energy Fuel 6, $681-693$ 
Mochida, I., Sakanishi, K., Suzuki, N., Sakurai, M., Tsukui, Y., Kaneko, T., 1998. Catalyst Surveys from Japan, 2, 17-30.

Quimby, V., Giarrocco, J., McCleary, K. A., 1993. HRC \& CC. $15,705-709$

Schmichitter, J. M., Vajta, Z., Arpino, P. J., 1979. Advances in Organic Gheochemistry, Pergamon Press Oxford, 1980, 67 - 76
Yanai, S., Komatsu, N., Shimasaki, K., 1998.

Proceeding, The 6th Japan - China

Symposium on Coal and C1 Chemistry, Miyagi, Japan, 196 - 199

Whitehurst,D.D; Isoda, T.; Mochida,I. 1998. Advanced Catalyst. 42,345-471 